\title{
Caracterização citogenética para identificação dos níveis de ploidia em cinco espécies do gênero Mentha L.
}

\author{
BATTISTIN, A"; ALMEIDA, A.L.S.M.2; NOGUEIRA,I.D.2; PASQUETTI, M.V.3; GONÇALVES, R.S.4; FERMINO \\ M.H. ${ }^{5}$; SILVEIRA, R.P. ${ }^{6}$. \\ ${ }^{1}$ Bióloga Dra. em Agronomia Pesquisadora voluntária da Fundação Estadual de Pesquisa Agropecuária.Rua \\ Gonçalves Dias, 570, B.Menino Deus, CEP: 90130-060. Porto Alegre-RS, Brasil. alibattistin@gmail.com, autor para \\ correspondência; ${ }^{2}$ Bolsista FAPERGS aluna da Universidade Estadual do Rio Grande do Sul, Rua Inconfidentes, \\ 395, CEP: 93340-140, Novo Hamburgo, RS, Brasil; ${ }^{3}$ Aluna de Ciências Biológicas da Universidade Federal do \\ Rio Grande do Sul, Rua Edmundo Bitencourt, 87/401, CEP 90110-050, Porto Alegre, RS, Brasil; ${ }^{4} B e l$. Química Dr. \\ Físico-química Universidade Federal do Rio Grande do Sul, Instituto de Química CEP: 91501-970 Porto Alegre, \\ RS, Brasil; ${ }^{5}$ Eng. Agro. Dra. em Fitotecnia, Fundação Estadual de Pesquisa Agropecuária, Rua Gonçalves Dias, \\ 570, CEP: 90130-060, Porto Alegre, RS, Brasil; ${ }^{6}$ Eng. Agro. Dr. em Fitopatologia, Fundação Estadual de Pesquisa \\ Agropecuária, Rua Gonçalves Dias, 570, CEP: 90130-060, Porto Alegre,RS,Brasil.
}

\begin{abstract}
RESUMO: Neste trabalho foi feita a caracterização citogenética da: microsporogênese, tétrades, estimativa da viabilidade do pólen pelo método de coloração e contagem do número máximo de nucléolos por célula interfásica, para identificação dos níveis de ploidia, em cinco espécies do gênero Mentha L. Foram coletadas inflorescências em 30 plantas de cada espécie, em duas florações sucessivas, nos anos 2006 e 2007. As inflorescências foram tratadas em etanol-ácido acético (3:1), em temperatura ambiente durante seis horas, transferidas para álcool $70 \%(\mathrm{v} / \mathrm{v})$ e conservadas em geladeira até análise. Nas análises da microsporogênese, tétrades e pólen o corante usado foi carmin propiônico $2 \%$ e na identificação dos nucléolos nitrato de prata $\left(\mathrm{AgNO}_{3}\right)$. Os resultados demonstraram que as cinco espécies são poliplóides. $M$. crispa heptaplóide $(2 n=7 x=84)$ com 11 nucléolos, $M$. spicata tetraplóide $(2 n=4 x=48)$ com 8 nucléolos, $M$.x gentilis pentaplóide $(2 \mathrm{n}=5 \mathrm{x}=60)$ com 12 nucleólos, M. piperita e M.x piperita ambas hexaplóides $(2 \mathrm{n}=6 \mathrm{x}=72)$ com 8 e 9 nucléolos respectivamente. $M$. spicata e $M$. crispa mantiveram as mais altas porcentagens de células normais na microsporogênese, na formação de tétrades e na estimativa da viabilidade do pólen por coloração, sugerindo maior estabilidade meiótica quando comparados aos demais poliplóides estudados.
\end{abstract}

Palavras-chave: microsporogênese, cromossomos, poliploidia, Mentha.

ABSTRACT: Citogenetic characterization to determination of ploidy level on five Mentha L. species. The cytogenetic characterization of five species of Mentha L. genus, including the data: regularity of microsporogenesis and tetrads, and polen viability, using the coloration method and the counting of the maximum number of nucleolus by interphasic cell were carried out in this study to identify the ploid levels. These analyses were performed from inflorescences collected in 30 plants of each species, during two successive florations in 2006 and 2007. Inflorescences were treated in 3:1 ethanol:acetic acid mixture at room temperature during six hours, then transferred to $70 \%(\mathrm{v} / \mathrm{v})$ ethanol solution and refrigerated until the analysis. For microsporogenis, tetrad and pollen analysis, we used carmine propionic $2 \%(\mathrm{~m} / \mathrm{v})$ and for nucleolus identification, we used $\mathrm{AgNO}_{3}$ solution. It was possible to observe that all five species were polyploids. $M$. crispa heptaploid $(2 n=7 x=84)$ with 11 nucleolus, $M$. spicata tetraploid $(2 \mathrm{n}=4 \mathrm{x}=48)$ with 8 nucleolus, $M$. $x$ gentilis pentaploid $(2 \mathrm{n}=5 \mathrm{x}=60)$ with 12 nucleolus, $M$. piperita and $M$. $x$ piperita both hexaploid $(2 \mathrm{n}=6 \mathrm{x}=72)$ with 8 and 9 nucleolus respectively. $M$. spicata and $M$. crispa kept the highest percentual values of normal cells in microsporogenesis as well as in tetrads formation and pollen viability, suggesting a higher meiotic stability when compared to the other polyploids studied.

Keywords: microsporogenesis, chromosome, polyploid, Mentha.

Recebido para publicação em 07/06/2011 


\section{INTRODUÇÃO}

O gênero Mentha pertence à família Lamiaceae, com aproximadamente 25 espécies conhecidas vulgarmente por hortelãs. São originárias da Europa e Ásia, tendo sido introduzidas no Brasil na época do descobrimento. O gênero Mentha é taxonomicamente complexo devido à existência de plasticidade fenotípica e à variabilidade genética (Halliday \& Beadle, 1972; Dorman et al. 2003). As espécies possuem grande facilidade de hibridização, o que gera problemas de identificação, por apresentarem características muito semelhantes.

Agenética, através de técnicas citogenéticas, busca informações diretamente relacionadas à ontogenia e filogenia dos seres vivos, usando como alvo principal os cromossomos, que constituem o próprio material genético em ação e transformação. Gobert et al. (2002), na tentativa de estabelecer uma filogenia de cinco espécies e três híbridos do gênero Mentha reunidos em 62 acessos, provenientes de diferentes regiões geográficas, fizeram análises citogenéticas, moleculares e morfológicas e propuseram que no gênero Mentha o número básico de cromossomos seja, provavelmente, $n=x=12$ e que, deste número, se originaram os diplóides $M$. suaveolens e $M$. longifolia com $2 n=2 x=24$ cromossomos. Estas duas espécies teriam sido as ancestrais das demais espécies com vários poliplóides (triplóides, tetraplóides, pentaplóides, hexaplóides e octoplóides), por hibridação entre espécies ou por sucessivas poliploidizações. Em algumas espécies foram encontrados citotipos, como em $M$. arvensis, onde há um citotipo com $2 n=72$ e outro com $2 n=96$ cromossomos. A $M$. arvensis se hibridiza com todas as outras espécies da seção, originando novos híbridos. Por exemplo, da $M$. arvensis $(2 n=72) \times M$. spicata $(2 n=48)$ resultou o pentaplóide $M$. gracilis $(2 n=5 x=60)$. Khanuja et al. (2000) utilizaram marcadores RAPD (Random Amplified Polymorphic DNA) para determinar padrões de similaridade genética entre $M$. arvensis, M. spicata, M. spicata cv. viridis, M. piperita, $M$. piperita cv. citrata, M. gracilis cv. cardíaca. Padrões únicos foram observados para cada uma das seis espécies de Mentha, indicando que marcadores RAPD podem ser usados para diferenciação das espécies.

Fatores importantes que influenciam no comportamento destas espécies devem ser levados em consideração, tais como: genético, características ambientais e ecológicas, práticas agronômicas e condições edafoclimáticas. Algumas das espécies produzem pouca ou nenhuma semente, as que produzem geralmente são estéreis. Desse modo, a multiplicação dessas espécies se faz via parte vegetativa: estolões, ramos e mudas (Battistin et al. 2011).
Outro parâmetro genético que auxilia na diferenciação das espécies são os nucléolos, componentes celulares onde o DNA transcreve RNAr que por sua vez, está diretamente relacionado com a síntese de proteínas. Nestas regiões os genes transcricionais estão ativos, caracterizando cada uma das espécies, porém podem ocorrer sítios não ativos/silenciosos, principalmente em espécies híbridas, que não são detectados pela técnica AgNOR, necessitando aplicação da técnica de rDNA-FISH. O número e o tamanho dos nucléolos, geralmente indicam a quantidade de genes ribossomais ativos (Lovatto \& Battistin, 1997; Battistin et al. 1999; Sumner, 2003).

Neste trabalho foi feita a caracterização citogenética: das regularidades da microsporogênese, das tétrades de micrósporos, estimativa indireta da viabilidade do pólen pelo método de coloração e contagem do número máximo de nucléolos por célula interfásica com o objetivo de identificar os diferentes níveis de ploidia das espécies: Mentha crispa L. S.F. Smith, Mentha spicata L. S.F. Smith, Mentha $x$ gentilis L. S.F. Smith, Mentha piperita L. e Mentha x piperita L. R. Morales Valverde.

\section{MATERIAL E MÉTODOS}

As mudas foram adquiridas de produtor estabelecido no município de Harmonia/RS/BR, com os nomes vulgares de: menta crespa, menta folha estreita, menta levante, menta piperita e hortelã. Trinta plantas de cada espécie foram cultivadas na Estação Experimental Eldorado-do-Sul-FEPAGRO (Fundação Estadual de Pesquisa Agropecuária) RS/ BR. Pelo fato das espécies apresentarem poucas sementes e a maioria estéreis, a multiplicação foi feita via parte vegetativa - estolões (Battistin et al. 2011). A identificação botânica foi registrada nos herbários: HUCS - Herbário Universidade Caxias do Sul e BLA-Brazilian Laboratory of Agrostology - FEPAGRO-Fundação Estadual de Pesquisa Agropecuária/RS. No registro constam as espécies com os respectivos números de identificação: Mentha crispa L. S.F. Smith HUCS-26629; BLA17254; Mentha spicata L. S.F. Smith HUCS 26628; Mentha x gentilis L. S.F. Smith HUCS-26627; Mentha piperita L. HUCS 26627 e BLA-17255; Mentha x piperita L. R. Morales Valverde HUCS-27666 (Battistin et al, 2011).

Para caracterização citogenética, foram coletadas 30 inflorescências (uma em cada planta) em cada espécie, em duas florações sucessivas, nos anos 2006 e 2007, fixadas em etanol-ácido acético (3:1), mantidas em temperatura ambiente durante seis horas, transferidas para álcool $70 \%$ $(\mathrm{v} / \mathrm{v})$ e conservadas em geladeira até análise. $\mathrm{Na}$

Rev. Bras. PI. Med., Campinas, v.15, n.4, supl.I, p.684-691, 2013. 
observação das fases da microsporogênese, das 30 inflorescências de cada ano, foram escolhidos, ao acaso, 10 botões florais com células em meiose, 6 botões florais com células na fase de tétrades, e 7 botões florais com células na fase de pólen.

Cada botão floral foi esmagado no corante carmin propiônico $2 \%(\mathrm{~m} / \mathrm{v})$. Os dados obtidos das fases da meiose com os cromossomos em associação e disjunção na meiose I e II foram expressos em porcentagem entre anos dentro de cada espécie. Uma tétrade foi considerada normal quando, no final da meiose, o quarteto era formado de quatro micrósporos iguais. Foi usado o corante carmin propiônico para inferir, de forma indireta, a viabilidade dos grãos de pólen, mediante a coloração. A viabilidade do pólen foi determinada pelo tamanho e uniformidade de coloração do protoplasma. As porcentagens dos dados da normalidade das tétrades e viabilidade do pólen foram analisadas em cada floração e entre florações em cada espécie pelo teste Tukey (nível 5\%).

Em 120 células interfásicas, foi feita a contagem do número máximo de nucléolos por núcleo, usando-os como parâmetro diferencial entre as espécies. Os nucléolos foram corados e identificados com $\mathrm{AgNO}_{3}$ (nitrato de prata) $50 \%$ $(\mathrm{m} / \mathrm{v})$.

\section{RESULTADOS E DISCUSSÃO}

Nas análises da microsporogênese, nas cinco espécies, as células em divisão apresentaram uma porcentagem de normalidade compreendida entre $52,66 \%$ e $100 \%$ na meiose I e II nas fases de associação e disjunção dos cromossomos. Com exceção de $M$. piperita, e M. x piperita nos demais poliplóides a porcentagem de células normais em associação - diacinese e metáfase I - foi menor no segundo ano, quando comparado com a produção no primeiro ano. Na disjunção dos cromossomos anáfase e telófase I, Mentha spicata foi a única espécie que manteve $100 \%$ células normais nas duas florações. Na disjunção - anáfase e telófase II - M. spicata manteve $100 \%$ de células normais na primeira floração e $M$. piperita manteve maior número de células normais $(100 \%)$ na segunda floração, nas demais espécies a porcentagem diminuiu no segundo ano (Tabela 1).

M. crispa apresentou em diacinese 42 cromossomos pareados, portanto o número total

TABELA 1. Análise da microsporogênese de: Mentha crispa, Mentha spicata, Mentha x gentilis, Mentha piperita e Mentha x piperita, em duas florações sucessivas, anos 2006 - 2007.

\begin{tabular}{|c|c|c|c|c|c|c|c|c|c|c|c|c|c|c|}
\hline & & & \multirow{2}{*}{\multicolumn{6}{|c|}{ Meiose I }} & & & & & & \\
\hline & & \multirow{5}{*}{$\begin{array}{c}\mathrm{N}^{0} \text { de } \\
\text { amostras }\end{array}$} & & & & & & & \multicolumn{6}{|c|}{ Meiose II } \\
\hline & & & \multicolumn{3}{|c|}{ Associação } & \multicolumn{3}{|c|}{ Disjunção } & \multicolumn{3}{|c|}{ Associação } & \multicolumn{3}{|c|}{ Disjunção } \\
\hline \multirow{3}{*}{ Espécie } & \multirow{3}{*}{ Floração } & & & acine & se e & & náfas & & \multicolumn{3}{|c|}{ Metáfase II } & \multirow{2}{*}{\multicolumn{3}{|c|}{$\begin{array}{c}\text { Anáfase e telófase } \\
\text { II }\end{array}$}} \\
\hline & & & & & & & & & & & & & & \\
\hline & & & $\mathrm{N}^{*}$ & $\mathrm{~N}^{* *}$ & $\%$ & $\mathrm{~N}^{*}$ & $\mathrm{~N}^{* *}$ & $\%$ & $\mathrm{~N}^{*}$ & $\mathrm{~N}^{* *}$ & $\%$ & $\mathrm{~N}^{*}$ & $\mathrm{~N}^{*}$ & $\%$ \\
\hline \multirow{2}{*}{ Mentha crispa $L$. } & $1^{\mathrm{a}}(2006)$ & 10 & 248 & 09 & 96,49 & 205 & 32 & 83,90 & 56 & 02 & 96,43 & 123 & 11 & 92,17 \\
\hline & $2^{\mathrm{a}}(2007)$ & 10 & 203 & 25 & 91,37 & 215 & 14 & 94,32 & 36 & 03 & 95,28 & 52 & 12 & 85,48 \\
\hline \multirow{2}{*}{ Mentha spicata L. } & $1^{\mathrm{a}}(2006)$ & 10 & 206 & 11 & 95,92 & 33 & 00 & 100 & 249 & 05 & 96,25 & 42 & 00 & 100 \\
\hline & $2^{\mathrm{a}}(2007)$ & 10 & 125 & 24 & 86,00 & 37 & 00 & 100 & 336 & 20 & 94,71 & 179 & 13 & 92,32 \\
\hline \multirow{2}{*}{ Mentha $\mathrm{x}$ gentilis L. } & $1^{\mathrm{a}}(2006)$ & 10 & 249 & 05 & 96,25 & 336 & 20 & 94,71 & 42 & 00 & 100 & 179 & 13 & 92,32 \\
\hline & $2^{\mathrm{a}}(2007)$ & 10 & 143 & 27 & 82,34 & 61 & 22 & 78,30 & 27 & 05 & 62,63 & 42 & 14 & 77,16 \\
\hline \multirow{2}{*}{ Mentha piperita L. } & $1^{\mathrm{a}}(2006)$ & 10 & 365 & 44 & 87,38 & 184 & 07 & 96,36 & 27 & 02 & 96,43 & 60 & 09 & 88,47 \\
\hline & $2^{\mathrm{a}}(2007)$ & 10 & 286 & 08 & 96,23 & 484 & 16 & 97,94 & 58 & 02 & 97,83 & 93 & 00 & 100 \\
\hline \multirow{2}{*}{ Mentha x piperita L. } & $1^{\mathrm{a}}(2006)$ & 10 & 207 & 65 & 71,80 & 791 & 60 & 93,20 & 40 & 00 & 100 & 63 & 40 & 60,48 \\
\hline & $2^{\mathrm{a}}(2007)$ & 10 & 274 & 92 & 75,12 & 210 & 41 & 82,91 & 40 & 00 & 100 & 77 & 63 & 52,66 \\
\hline
\end{tabular}

$\mathrm{N}^{*}=\mathrm{N}^{0}$. de células normais. $\mathrm{N}^{* *}=\mathrm{N}^{0}$. de células com anormalidades. $\%$ de células normais. 
de cromossomos é 84 (Figura 1A e Tabela 2). $\mathrm{O}$ mesmo número foi sugerido por Harley \& Brighton (1977). Morton (1956) fez uma criteriosa contagem e identificação do número de cromossomos de poliplóides e híbridos do gênero Mentha, baseado no material coletado em várias regiões da Grã-Bretanha. Concluiu que $M$. crispa, pode ser uma variedade de $M$. aquatica ou um híbrido entre variedades de $M$. spicata ou, ainda, híbrido entre $M$. spicata $e$ M. rotundifolia. Segundo Dimech et al. (2006), M. crispa é um híbrido originário de $M$. spicata $(2 \mathrm{n}=48)$ e $M$. suaveolens $(2 n=24)$. Os mesmos autores afirmaram que $M$. crispa, é conhecida popularmente como hortelã-de-folha-miúda. Pelos resultados encontrados no nosso trabalho, admitimos que M. crispa é um heptaplóide com $2 n=7 x=84$ cromossomos (Tabela 2), que provavelmente se originou por alopoliploidia tendo seus genitores $n=12$ cromossomos. Foram encontrados cromossomos univalentes na diacinese e metáfase I que se comportaram como retardatários na anáfase I, e algumas células com um cromossomo retardatário na anáfase II (Tabela 1). Nas duas florações as células em microsporogênese mantiveram uma normalidade acima de $83 \%$, tétrades normais acima de $65 \%$ (Tabela 3) e pólen considerado normal acima de $92 \%$ (Tabela 4). O número máximo de nucléolos encontrado em cada célula interfásica foi 11 (Figura 1B e Tabela 2), sugerindo 11 regiões organizadoras nucleolares expressando seus genes ribossomais ativos, situados nas constrições secundárias.

M. spicata possui 48 cromossomos, sendo visualizados 24 em cada pólo na telófase I (Figura 1C e Tabela 2). Para Tucker, (1992), $M$. spicata é um tetraplóide natural $(2 n=4 x=48)$, porém para Gobert et al. (2002), M. spicata é um hibrido entre $M$. suaveolens $(2 n=24)$ e $M$. longifólia $(2 n=24$ ou 48$)$; no mesmo trabalho, os autores admitem a existência de grande variabilidade dentro da $M$. spicata, e através de estudos citológicos constataram a existência de dois citotipos entre os híbridos: um grupo triplóide com $2 n=36$ e outro grupo tetraplóide com $2 \mathrm{n}=48$ cromossomos. Nosso trabalho confirma ser uma espécie tetraplóide $(2 n=4 x=48)$. Este tetraplóide provavelmente se originou por autopoliploidia, ou seja, pela multiplicação de um conjunto cromossômico básico $(n=12)$, tendo acima de $86 \%$ de células normais em diacinese e metáfase I; $100 \%$ normais em anáfase e telófase I; e, acima de $92 \%$ normais em anáfase e telófase II (Tabela 1 ). Irregularidades encontradas na microsporogênese neste tetraplóide foram um/dois cromossomos fora da placa equatorial nas metáfases I e II e poucas células com um cromossomo retardatário na disjunção: anáfase e telófase II na segunda floração. Foram observadas acima de $88 \%$ de tétrades normais (Tabela 3 ) nos dois anos de floração. Quanto à viabilidade do pólen (Tabela 4) ocorreu uma diferença significativa entre os dois anos de produção sendo de $88,48 \%$ a viabilidade no primeiro ano, mostrando superioridade no segundo ano $96,18 \%$. Estas diferenças provavelmente podem ser atribuídas a fatores ambientais influenciando sobre os genótipos. O número máximo de nucléolos em cada célula interfásica é igual a oito (Figura 1D e Tabela 2), indicando oito regiões organizadores nucleolares (NORs) com os genes ribossomais ativos.

Mentha $x$ gentilis apresentou 30 cromossomos pareados na diacinese da meiose (Figura 1E e Tabela 2), possuindo um total de 60 cromossomos nas células somáticas. O número proposto por Harley \& Brighton (1977), foi de 84 cromossomos, sendo um híbrido de $M$. arvensis $(2 n=6 x=72)$ com $M$. spicata $(2 n=4 x=48)$, originário da Inglaterra. Enquanto que para Gobert et al. (2002) é um híbrido de $M$. arvensis $(2 n=72)$ com $M$. spicata $(2 n=36)$. No nosso trabalho constatamos que Mentha $x$ gentilis é um pentaplóide com $2 n=5 x=60$ (Tabela 2). Sua origem ainda não está esclarecida, mas como os resultados mostraram acentuadas irregularidades nas fases da meiose, baixa formação de tétrades e de pólen normal, estes dados sugerem que o poliplóide se originou por alopoliploidia e provavelmente seus genitores possuem $n=12$ cromossomos. A porcentagem de células normais em todas as fases da microsporogênese (Tabela 1) foi superior no primeiro ano, caindo dràsticamente no segundo ano. Das irregularidades encontradas predominaram cromossomos univalentes na diacinese e metáfase I, células com um ou dois cromossomos retardatários em anáfase/telófase I e II, algumas células com um/dois cromossomos fora da placa equatorial na metáfase II no segundo ano. A porcentagem de tétrades anormais (Tabela 3) foi superior à porcentagem de tétrades normais tanto no primeiro como no segundo ano de floração. A viabilidade do pólen (Tabela 4) no primeiro ano foi $77,47 \%$, caindo dràsticamente no segundo ano atingindo uma porcentagem de $27,18 \%$. O número máximo de nucléolos por célula interfásica foi 12 (Figura 1F e Tabela 2), indicando 12 regiões organizadoras nucleolares expressando seus genes ribossomais ativos.

$\mathrm{Na}$ Mentha piperita foram visualizados 36 cromossomos pareados em diacinese da meiose (Figura 1G e Tabela 2) indicando que em cada célula somática há 72 cromossomos (Tabela 2 ), sendo um hexaplóide $(2 n=6 x=72)$. O mesmo número foi proposto por Krasnyanski et al. (1998). Já para Morton (1956), M. piperita com 72 cromossomos surgiu do cruzamento entre $M$. spicata com 48 cromossomos e $M$. aquatica com 96 cromossomos. Segundo Stasi et al. (2002) esta espécie, originária

Rev. Bras. PI. Med., Campinas, v.15, n.4, supl.I, p.684-691, 2013. 
da Inglaterra, é um hibrido entre $M$. viridis e $M$. aquatica, enquanto que Glotov (1940) propôs ser um triplóide $(2 n=3 x=64)$ que em condições naturais é estéril. Na microsporogênese (Tabela 1), tanto nas fases de associação como nas fases de disjunção a porcentagem de células normais ficou entre $87,38 \%$ a $100 \%$. Embora as fases da microsporogênese, ocorreram de uma forma normal, isto não aconteceu na formação das tétrades (Tabela 3 ) onde a normalidade caiu dràsticamente nos dois anos consecutivos, sendo $7,19 \%$ no primeiro ano e $15,62 \%$ no segundo ano. Isto refletiu numa diminuição na porcentagem de viabilidade de pólen que foi apenas $67,50 \%$ no primeiro ano e $75,30 \%$ no segundo ano (Tabela 4). Esta discrepância de dados sugere a existência de genes específicos letais, e/ou fortemente influenciados pelo meio ambiente que se manifestam no final da meiose, ou seja no momento da formação de tétrades. $O$ número máximo de nucléolos por núcleo em células interfásicas foi oito (Figura $1 \mathrm{H} \mathrm{e}$ Tabela 2), sugerindo oito regiões organizadoras nucleolares, situadas nas constrições secundárias, expressando seus genes ribossomais ativos.

Nas análises da meiose constatamos que Mentha x piperita, tem $2 n=72$ cromossomos (Tabela 2), contendo nas células normais em diacinese 36 pares de cromossomos (Figura 1I). Tucker (1992) e Simões et al (1998) levantaram a hipótese de que $M$. $x$ piperita L., poderia ser um tetraplóide $(2 n=4 x=72)$ que surgiu naturalmente pela hibridização entre M. aquatica L. $(2 \mathrm{n}=96)$ e M. spicata $(2 \mathrm{n}=48)$, por ser uma espécie estéril cuja multiplicação ocorre vegetativamente. Para Gobert et al. (2002) do cruzamento entre $M$. aquatica $L$. $(2 n=96)$ e $M$. spicata $(2 \mathrm{n}=48)$ surgiram 2 ecotipos diferentes: $M$. x piperita com $2 n=66$ e M. x piperita com $2 n=72$ cromossomos. Para Asmar et al (2011), a hortelãpimenta é um hibrido triplo, Mentha x piperita. Sendo o número básico do gênero $n=12$ cromossomos, pelos dados obtidos no nosso trabalho Mentha $\mathrm{x}$ piperita é um hexaplóide $(2 n=6 x=72)$. Provavelmente originou-se por alopoliploidia do cruzamento entre M. aquatica $(2 n=96) \times M$. spicata $(2 n=48)$, ambos genitores com $n=12$ cromossomos. É uma espécie considerada estéril pelo fato de formar muito poucas sementes. Nas fases de disjunção anáfase/telófase I a porcentagem de células normais foi de $93,20 \%$ na primeira floração e $82,91 \%$ na segunda floração, enquanto que na anáfase/telófase II ocorreu uma drástica diminuição de células normais em $60,48 \%$ na primeira floração com diminuição ainda maior na segunda floração $52,66 \%$. No saldo final do processo meiótico, tanto na primeira como na segunda floração, a porcentagem de células normais em Mentha x piperita foi a mais baixa quando comparada com as demais espécies estudadas, com apenas $52,66 \%$ na segunda floração, indicando uma perda de normalidade de $47,34 \%$ de células durante a divisão celular (Tabela 1). Ocorreram diferenças significativas na produção de tétrades normais e anormais (Tabela 3 ) nas duas florações, predominando as anormalidades, sendo que na segunda floração foi alcançada a porcentagem mais alta $69,72 \%$. Na formação do pólen, nos dados analisados estatisticamente não foi detectada diferença significativa entre as duas florações que mantiveram $67,90 \%$ e $67,50 \%$, respectivamente.

Foram observados no máximo nove nucléolos por núcleo em células interfásicas (Figura $1 \mathrm{~J}$ e Tabela 2), sugerindo nove regiões organizadoras nucleolares expressando seus genes ribossomais ativos.

As anormalidades encontradas no desenvolvimento da meiose nos cinco poliplóides foram: falta de pareamento de alguns cromossomos na diacinese formando univalentes, cromossomos fora da placa equatorial na metáfase I e II, cromossomos retardatário nas anáfases I e II. Estas anormalidades provavelmente são decorrentes da falta de homologia de alguns cromossomos, pelo fato das espécies em questão serem poliplóides. As discrepâncias, na ocorrência de anormalidades na microsporogênese, entre as cinco espécies

TABELA 2. Níveis de ploidia e número máximo de nucléolos em células interfásicas de $M$. crispa, M. spicata, M. x gentilis, M. piperita e M. x piperita.

\begin{tabular}{|c|c|c|c|c|}
\hline Espécie & $\begin{array}{c}\text { Haploidia } \\
\text { (n) }\end{array}$ & $\begin{array}{c}\text { Diploidia } \\
(2 n)\end{array}$ & Poliploidia & $\begin{array}{l}\text { № máximo nucléolos/ } \\
\text { célula interfásica }\end{array}$ \\
\hline Mentha crispa L. S.F. Smith & 42 & 84 & $2 n=7 x=84$ & 11 \\
\hline Mentha spicata L. S.F. Smith & 24 & 48 & $2 n=4 x=48$ & 08 \\
\hline Mentha $x$ gentilis L. S.F. Smith & 30 & 60 & $2 n=5 x=60$ & 12 \\
\hline Mentha piperita L. & 36 & 72 & $2 n=6 x=72$ & 08 \\
\hline Mentha $x$ piperita L. R. M.Valverde & 36 & 72 & $2 n=6 x=72$ & 09 \\
\hline
\end{tabular}

Rev. Bras. PI. Med., Campinas, v.15, n.4, supl.I, p.684-691, 2013. 
em questão, é um indicativo de serem poliplóides de origens diferentes: a) autopoliplóides indivíduos que apresentam número múltiplo exato do genoma característico da espécie: Mentha spicata (tetraplóide); b) alopoliplóides - indivíduos originados da combinação de genomas diferentes: Mentha piperita e Mentha x piperita (hexaplóides), Mentha crispa (heptaplóide) e Mentha x gentilis (pentaplóide).

Em relação à quantidade de tétrades normais (Figura 2A) e anormais, $M$. crispa e $M$. spicata mantiveram suas porcentagens equilibradas nas duas florações, não havendo diferenças significativas dentro de cada espécie entre as florações. Entretanto, ocorreram diferenças significativas entre normais e anormais, prevalecendo maior porcentagem de normalidades, sendo a mais alta observada na $M$. spicata $(91,60 \%)$. Nos demais poliplóides: $M$. piperita, $M$. x gentilis e M. x piperita nas duas florações, dentro de cada poliplóide verificaram-se diferenças significativas nas médias das porcentagens (Tabela 3), tanto para as normais como para as anormais, prevalecendo maior porcentagem de anormais, sendo a mais alta encontrada na $M$. piperita com $92,81 \%$ na primeira floração. Entre as anormalidades foram encontradas: hexíades, pentíades, tríades e díades, (Figuras. 2B, 2C, 2D, 2E).

Nas colunas letras minúsculas diferentes dentro da espécie indicam diferença significativa entre florações dentro da espécie. Nas linhas Letras maiúsculas diferentes dentro da espécie indicam diferença significativa em cada espécie, em cada floração (Tukey, nível 5\%).

Quanto à estimativa indireta da viabilidade do pólen (Tabela 4), M. spicata e M. crispa também apresentaram as mais altas porcentagens, acima de $88 \%$, sobressaindo-se $M$. spicata $(96,18 \%)$ na segunda floração. Os demais poliplóides também mantiveram mais altas porcentagens significativas de pólen normal, com exceção de $M$. x gentilis que na segunda floração a normalidade caiu drasticamente $(27,18 \%)$.

M. piperita, $M$. x gentilis e $M$. x piperita foram às espécies que tiveram maiores instabilidades meióticas, conseqüentemente refletindo menores porcentagens de tétrades normais (Figura 2A) e viabilidade polínica. (Figuras 2F, 2G).

O gênero Mentha L. na domesticação de plantas, é considerado antigo, pelo fato de existirem relatos do uso de suas plantas desde a antiguidade pelos egípcios, hebreus, gregos e medievais para fins medicinais, aromáticos e condimentares. Diante dos resultados obtidos neste trabalho, constatamos que as cinco espécies são poliplóides com diferentes níveis de ploidias. Pelo fato de serem plantas poliplóides, consideráveis anormalidades ocorrem durante a meiose, levando à formação de gametas com um número de cromossomos não balanceado, tornando-os inviáveis. Provavelmente devem ocorrer irregularidades também na macrosporogênese, nos cinco poliplóides em questão justificando a baixa produção de sementes sendo a maioria estéril e inviável. A estratégia usada nestas espécies para manutenção de sucessivas gerações é a reprodução vegetativa. Sugerimos que o tetraplóide M. spicata e o heptaplóide M. crispa, possuem maior adaptabilidade (genética/ambiental), quando comparados aos demais poliplóides estudados, pelo fato de apresentarem porcentagens mais altas de células normais e manterem uma estabilidade constante na microsporogênese, nas tétrades e na estimativa da viabilidade do pólen, nos dois anos consecutivos analisados.

Nossos dados sugerem também que dentro do gênero Mentha, a poliploidização deve ter sido um evento muito forte na formação das espécies, originando vários tipos de poliplóides:

TABELA 3. Tétrades normais e anormais de: M. crispa, M. spicata, $M . x$ gentilis, M. piperita e M. x piperita. 1a e 2a floração. Anos 2006 e 2007.

\begin{tabular}{|c|c|c|c|c|c|c|c|}
\hline \multicolumn{8}{|c|}{ Tétrades } \\
\hline Espécies & Floração & $\mathrm{N}^{\circ}$ de Amostras & Normais & Anormais & Total & $\%$ normais & $\%$ anormais \\
\hline \multirow{2}{*}{ M. crispa L. } & $1^{\mathrm{a}}(2006)$ & 6 & 438 & 249 & 687 & $65,46^{\mathrm{aA}}$ & $34,54^{\mathrm{a} B}$ \\
\hline & $2^{\mathrm{a}}(2007)$ & 6 & 484 & 264 & 748 & $66,60^{\mathrm{a} A}$ & $33,40^{\mathrm{a} \mathrm{B}}$ \\
\hline \multirow{2}{*}{ M. spicata L. } & $1^{\mathrm{a}}(2006)$ & 6 & 356 & 31 & 387 & $91,60^{\mathrm{aA}}$ & $8,40^{\text {a }}$ \\
\hline & $2^{\mathrm{a}}(2007)$ & 6 & 703 & 92 & 795 & $88,67^{\mathrm{aA}}$ & $11,33^{a \mathrm{~B}}$ \\
\hline \multirow{2}{*}{ M. piperita L. } & $1^{a}(2006)$ & 6 & 96 & 1.240 & 1.341 & $7,19^{\mathrm{b} \text { в }}$ & $92,81^{\mathrm{bA}}$ \\
\hline & $2^{a}(2007)$ & 6 & 230 & 1.213 & 1.443 & $15,62^{\mathrm{aA}}$ & $84,38^{\mathrm{a} B}$ \\
\hline \multirow{2}{*}{ M. $\times$ gentilis $\mathrm{L}$. } & $1^{\mathrm{a}}(2006)$ & 6 & 359 & 638 & 997 & $35,90^{\text {b B }}$ & $64,10^{\mathrm{b} A}$ \\
\hline & $2^{a}(2007)$ & 6 & 263 & 287 & 550 & $46,21^{\mathrm{aB}}$ & $53,79^{\mathrm{aA}}$ \\
\hline \multirow{2}{*}{ M. x piperita L. } & $1^{\mathrm{a}}(2006)$ & 6 & 239 & 369 & 662 & $43,74^{a \mathrm{~B}}$ & $56,26^{\mathrm{bA}}$ \\
\hline & $2^{\mathrm{a}}(2007)$ & 6 & 127 & 361 & 488 & $30,28^{\mathrm{b} \mathrm{B}}$ & $69,72^{\mathrm{aA}}$ \\
\hline
\end{tabular}

Rev. Bras. PI. Med., Campinas, v.15, n.4, supl.I, p.684-691, 2013. 
TABELA 4. Pólen viável e inviável de: M. crispa, M. spicata, M. x gentilis, M. piperita e M. x piperita. $1^{\mathrm{a}}$ e $2^{\mathrm{a}}$ floração. Anos 2006 e 2007.

\begin{tabular}{|c|c|c|c|c|c|c|c|}
\hline \multicolumn{8}{|c|}{ Pólen } \\
\hline Espécies & Floração & $\mathrm{N}^{\circ}$ de Amostras & Viável & Inviável & Total & \% Viável & \% Inviável \\
\hline \multirow{2}{*}{ M. crispa L. } & $1^{a}(2006)$ & 7 & 2.560 & 168 & 2.728 & $93,74^{\mathrm{aA}}$ & $6,26^{\mathrm{a} B}$ \\
\hline & $2^{\mathrm{a}}(2007)$ & 7 & 2.585 & 217 & 2.802 & $92,46^{\mathrm{a} A}$ & $7,54^{\mathrm{a} \mathrm{B}}$ \\
\hline \multirow{2}{*}{ M. spicata L. } & $1^{a}(2006)$ & 7 & 1.024 & 111 & 1.135 & $88,48^{\mathrm{bA}}$ & $11,52^{\mathrm{a} B}$ \\
\hline & $2^{a}(2007)$ & 7 & 3.229 & 132 & 3.361 & $96,18^{\mathrm{aA}}$ & $3,82^{\mathrm{b} \mathrm{B}}$ \\
\hline \multirow{2}{*}{ M. piperita L. } & $1^{a}(2006)$ & 7 & 3.847 & 1.980 & 5.827 & $67,50^{\mathrm{aA}}$ & $32,50^{a} \mathrm{~B}$ \\
\hline & $2^{a}(2007)$ & 7 & 4.059 & 1.220 & 5.279 & $75,30^{\mathrm{aA}}$ & $24,70^{\mathrm{a} B}$ \\
\hline \multirow{2}{*}{ M. x gentilis L. } & $1^{a}(2006)$ & 7 & 2.292 & 745 & 3.037 & $77,47^{\mathrm{aA}}$ & $22,53^{\mathrm{b} B}$ \\
\hline & $2^{a}(2007)$ & 7 & 1.190 & 3.139 & 4.329 & $27,18^{\mathrm{bB}}$ & $72,82^{\mathrm{aA}}$ \\
\hline \multirow{2}{*}{ M. x piperita $\mathrm{L}$. } & $1^{a}(2006)$ & 7 & 4.187 & 1.912 & 6.099 & $67,90^{\mathrm{aA}}$ & $32,10^{\mathrm{a} B}$ \\
\hline & $2^{a}(2007)$ & 7 & 4.470 & 2.209 & 6.679 & $67,50^{\mathrm{aA}}$ & $32.50^{\mathrm{a} B}$ \\
\hline
\end{tabular}

Nas colunas letras minúsculas diferentes dentro da espécie indicam diferença significativa entre florações dentro da espécie. Nas linhas Letras maiúsculas diferentes dentro da espécie indicam diferença significativa em cada espécie, em cada floração (Tukey, nível 5\%).
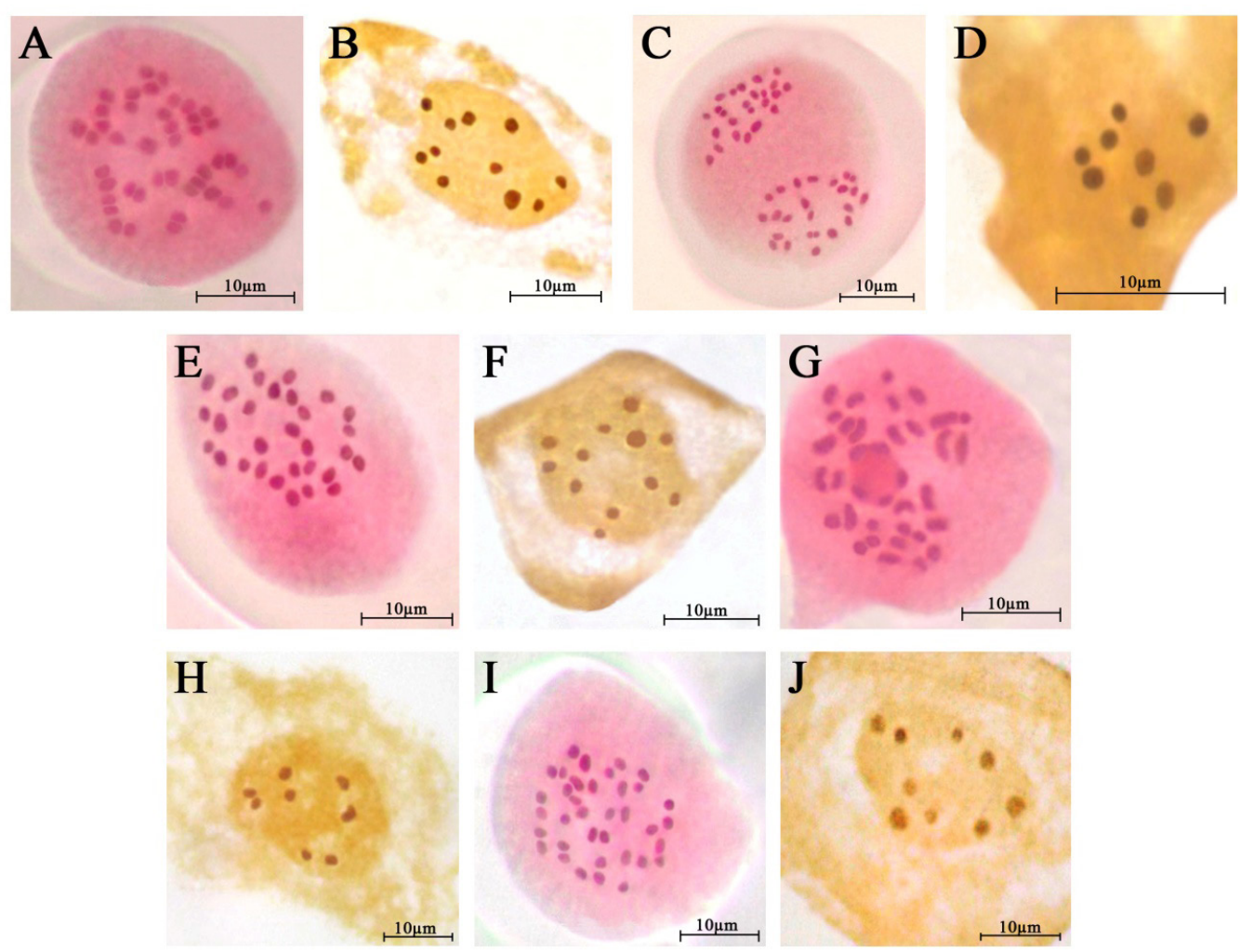

FIGURA 1. Microsporogênese e número máximo de nucléolos por célula em poliplóides de Mentha. (A-B) $M$. crispa: diacinese 42 bivalentes(II) e 11 nucléolos; (C - D) M. spicata: telófase I 24 bivalentes(II) e 8 nucléolos; (E - F) M. x gentilis: diacinese 30 bivalentes(II) e 12 nucléolos; $(\mathrm{G}-\mathrm{H})$ M. piperita: diacinese 36 bivalentes (II) e 8 nucléolos; (I - J) M. x piperita: diacinese 36 bivalentes (II) e 9 nucléolos.

autopoliplóides e alopoliplóides.

\section{AGRADECIMENTOS}

Os autores agradecem à Fundação Estadual de Pesquisa Agropecuária (FEPAGRO) e Universidade Federal do Rio Grande do Sul (UFRGS) pela disponibilidade dos equipamentos e do material; à Fundação de Amparo a Pesquisa do Estado do Rio Grande do Sul (FAPERGS) pelas bolsas concedidas. 



FIGURA 2. Irregularidades na formação de tétrades e pólen. A)Tétrade normal; B Hexíade; C) Pentíade; D) Tríade; E) Díade; F) Pólen viável; G) Pólen inviável.

\section{REFERÊNCIA}

ASMAR, S.A.; RESENDE, R.F; ARARUNA, E.C.; MORAIS, T.P.; LUZ, J.M.Q. Citocininas na multiplicação in vitro de hortelã-pimenta (Mentha x Piperita L.). Revista Brasileira de Plantas Medicinais, Botucatu, v.13, especial, p.533-538, 2011.

BATTISTIN, A.; BIONDO, E.; COELHO, L.G.M. Chromosomal characterization of three native and one cultivated species of Lathyrus L. in southern Brazil. Genetics and Molecular Biology, v.22, n.4, p.557563, 1999.

BATTISTIN, A.; FERMINO, M.H.;SILVEIRA,J.R.P.; GONÇALVES, R.S.; PASQUETTI, M.V.; SANTOS,de A.C.; ROTTA, L.; PAULETTI, G.; BARNI, V. Espécies de Mentha com propriedades medicinais, aromáticas e condimentares. Circular Técnica, FEPAGRO, Porto Alegre/RS, 2011, $31 \mathrm{p}$.

DIMECH, G.S.; GONÇALVES, E.S.; ARAUJO, A.V.; ARRUDA, V.M.; BARATELLA-EVÊNCIA, L.; WANDERLEY, A.G. Avaliação do extrato hidroalcoólico de Mentha crispa sobre a performance reprodutiva em ratos Wistar. Revista Brasileira de farmacognosia, v.16, n.2, p.152-157, 2006.

DORMAN, H.J.D; KOSAR, M.; KAHLOS, K.; HOLM, Y.; HILTUNEN, R. Antioxidant properties and composition of aqueous extracts from Mentha species, hybrids, varieties and cultivars. Journal of Agricultural and Food Chemistry, v.51, n.16, p.4563-4569, 2003.

GOBERT ,V.; MOJA, S.; COLSON, M.; TABERLET, P. Hybridization in the section Mentha (Laminaceae) inferred from AFLP markers. American Journal of Botany, v 89, n.12, p. 2017-2023, 2002.
GLOTOV, V. Amphidiploid fertile form of Mentha piperita L. produced by colchicine treatment. Doklad y Akademii Nauk SSSR, v.28, p.450-453, 1940.

HARLEY R.; BRIGHTON, C.A. Chromosome numbers in the genus Mentha L. Botanical Journal of the Linnean Society, v.74, p.71-96, 1977.

HALLIDAY, G.; BEADLE, M. Flora Europaea, v.3, p.185186, 1972.

KHANUJA, S.P.S.; SHASANY A.K.; SRIVASTAVA, A.; KUMAR, S. Assessment of genetic relationships in Mentha species. Euphytica, v.11, p.1121-125, 2000.

KRASNYANSKI, S.; BALL, T.M.; SINK, K.C. Somatic hybridization in mint: identification and characterization of Mentha piperita (+) M. spicata hybrid plants. Theoretical and Applied genetics , v.96, p.683-687, 1998.

LOVATTO, M.T.; BATTISTIN, A. Citogenética em cinco espécies ornamentais de Liliales. Ciência Rural, v 27, n 4, p.583-587, 1997.

MORTON, J.K. The chromosome numbers of the british Menthae. Watsonia, v.3, p.244-252, 1956.

SIMÕES, C.M.O.; MENTZ, L.A.; SCHENKEL, E.P.; IRGANG, B.E.; STEHMANN,J.R. Plantas da medicina popular no Rio Grande do Sul, Editora UFRGS, Porto Alegre,RS.1998.174 p

STASI ,D.L.C.; HIRUMA-LIMA, C.A.; GUIMARÃES, E.M.; SANTOS, C.M. Plantas Medicinais na Amazônia e na Mata Atlântica: Lamiales Medicinais. São Paulo: UNESP, 2002. 604 p.

SUMNER, A.T.. Chromosome organization and function. London: Unwn Hyman, 2003, 434p.

TUCKER, A.O. The truth about mints. The Herb Companion, v.4, p.51-52, 1992 